\title{
Language non-selective syntactic activation in early bilinguals: the effect of verbal fluency
}

Sanoudaki, E.; Thierry, G.

\section{International Journal of Bilingual Education and Bilingualism}

\author{
DOI: \\ 10.1080/13670050.2015.1027143
}

Published: 01/01/2015

Peer reviewed version

Cyswllt i'r cyhoeddiad / Link to publication

Dyfyniad o'r fersiwn a gyhoeddwyd / Citation for published version (APA):

Sanoudaki, E., \& Thierry, G. (2015). Language non-selective syntactic activation in early bilinguals: the effect of verbal fluency. International Journal of Bilingual Education and Bilingualism, 18(5), 548-560. https://doi.org/10.1080/13670050.2015.1027143

\footnotetext{
Hawliau Cyffredinol / General rights

Copyright and moral rights for the publications made accessible in the public portal are retained by the authors and/or other copyright owners and it is a condition of accessing publications that users recognise and abide by the legal requirements associated with these rights. study or research.

- Users may download and print one copy of any publication from the public portal for the purpose of private

- You may not further distribute the material or use it for any profit-making activity or commercial gain

- You may freely distribute the URL identifying the publication in the public portal?

Take down policy

This is an Accepted Manuscript of an article published by Taylor \& Francis in International Journal of Bilingual Education and Bilingualism, April 2015, available online: http://wwww.tandfonline.com/DOI 10.1080/13670050.2015.1027143.

Take down policy

If you believe that this document breaches copyright please contact us providing details, and we will remove access to the work immediately and investigate your claim.
} 


\title{
Language non-selective syntactic activation in early bilinguals: the effect of verbal fluency
}

\author{
Eirini Sanoudaki ${ }^{\mathrm{a}, \mathrm{b}, 1}$ and Guillaume Thierry ${ }^{\mathrm{a}, \mathrm{c}}$
}

${ }^{a}$ Centre for Research on Bilingualism, Bangor University. College Road, LL57 2DG, Bangor, Gwynedd, United Kingdom.

${ }^{b}$ School of Linguistics and English Language, Bangor University. College Road, LL57 2DG, Bangor, Gwynedd, United Kingdom.

${ }^{c}$ School of Psychology, Bangor University. Adeilad Brigantia, Penrallt Road, LL57 2AS, Bangor, Gwynedd, United Kingdom.

\section{Acknowledgements:}

We thank Dirk Bury, Benjamin Dering, Virginia Gathercole, Noriko Hoshino, Nia Jones, JanRouke Kuipers, Mark Roberts, Nicola Savill, Marco Tamburelli, Enlli Thomas, and Yanjing Wu for their assistance with this project. We are also grateful to the editors and to two anonymous reviewers for their helpful comments on earlier versions of the manuscript.

\section{Funding:}

This work was supported by the Economic and Social Research Council UK (ES/E024556/1). GT was supported the European Research Council (ERC-SG-209704), and the British Academy (BA-MD120036).

\footnotetext{
${ }^{1}$ Corresponding author. Email: e.sanoudaki@bangor.ac.uk
} 
Language non-selective syntactic activation in early bilinguals

Numerous studies have shown that bilinguals presented with words in one of their languages spontaneously and automatically activate lexical representations from their other language. However, such effects, found in varied experimental contexts, both in behavioural and psychophysiological investigations, have been essentially limited to the lexical-semantic domain. Using brain potentials in a mental decision task in early highly proficient Welsh-English bilinguals and English monolingual controls, a recent study suggests that language non-selective effects exist in the domain of syntax [Thierry and Sanoudaki 2012]. In this paper, we test whether syntactic access in bilinguals is affected by relative language abilities, as indexed by verbal fluency measures in the bilingual's two languages. Results reveal that non-selective syntax in English sentence comprehension is limited to bilinguals with higher Welsh verbal fluency. This result suggests for the first time directionality in cross-language syntactic activation in early bilinguals.

Keywords: bilingualism; syntactic processing; sentence comprehension; language non-selective access; event-related potentials; N200

\section{Introduction}

A question that has been central in the study of bilingualism is whether the two languages in a bilingual individual are accessed separately or whether there is simultaneous activation of the two languages. The interest in this question is linked to parents' concerns that bringing up their children bilingually could result in a disadvantage in language processing as compared to a monolingual upbringing, and it is motivated by the widely recognised need to investigate the little-known abilities of the bilingual mind.

In the context of these questions, the area of language activation in bilinguals has been extensively studied. A considerable body of research has shown that lexical access in one of the two languages is influenced by properties of the lexicon of the other language (Dijkstra, Grainger and van Heuven 1999; Dijkstra and van Heuven 2002; 
Duyck 2005; Jared and Kroll 2001; Kroll and Stewart 1994, amongst many others; see Kroll et al. 2012 for a review). There is now consensus that the lexica of the two languages are not accessed separately, and a range of phonological, semantic and orthographic similarities can trigger activation of one language when processing words in the other language of a bilingual individual. The phenomenon is not limited to adult bilinguals; evidence of non-selective lexical access has also been found in bilingual children as young as 2 years old (Holzen and Mani 2012). This cross-language lexical activation has been evidenced in a variety of experimental tasks, including, more recently, the technique of Event Related Potentials (henceforth ERPs, Thierry and Wu 2007, see also Wu and Thierry 2010). Thierry and $\mathrm{Wu}(2007)$ provided electrophysiological evidence, in the absence of behavioural effects, that ChineseEnglish bilinguals access their first language when processing words in English. Crosslanguage activation in the lexical domain is also established in production in bilingual adults (e.g. Costa, Miozzo, and Caramazza 1999, Hoshino and Kroll 2008) as well as children (e.g. Poarch and van Hell 2012).

In a recent study (Thierry and Sanoudaki 2012) we reported for the first time effects of language non-selective activation in early bilinguals extending to the domain of syntax. We tested early Welsh-English bilinguals and English monolingual controls in a picture - English sentence matching decision task. Participants saw sentences that contained adjective-noun pairs, and were instructed to respond only when either the adjective or the noun matched the characteristics of a preceding picture. As expected, when the adjective in the sentence did not match the picture, participants inhibited their response until after they could read the noun, as shown by a significant modulation of the N2 peak of ERPs. Surprisingly, however, when the noun was encountered first (i.e., in the case of noun-adjective sequences), only the Welsh-English bilinguals showed a 
response inhibition effect, indicating that they were ready to process an impending adjective in post-nominal position, even though this is ungrammatical in English. This effect provided evidence that knowledge of the post-nominal adjectival placement of Welsh syntax is fully accessible during the processing of sentences exclusively presented in English, suggesting that syntactic access in early bilinguals is language non-selective.

However, it is not known whether all bilingual participants in the Thierry and Sanoudaki (2012) study showed this response inhibition effect, or whether there were within-group differences depending on the bilinguals' relative abilities in their two languages. Research on lexical activation has detected bidirectional cross-language effects, including from the second to the native language (e.g. van Hell and Dijkstra 2002); however, it has occasionally unveiled asymmetrical effects, such that activation of the bilingual's first or more dominant language is more likely to be detected when words in the second or weaker language are being processed than the opposite (i.e., activation of the second or weaker language when words in the first language are being processed, e.g., Weber and Cutler 2004). The current paper is a first step towards examining whether the effect of language abilities on cross-language activation is also present in the case of syntactic processing. Here, we reanalyse the electrophysiological data from the mental decision task in our previous paper (Thierry and Sanoudaki 2012) to determine whether relative verbal fluency has an effect on the presence of nonselective syntactic activation.

Verbal fluency was selected as an objective measure of relative language abilities (Sandoval et al. 2010). Sandoval et al. (2010) tested semantic verbal fluency in the two languages of fifty-one Spanish-English bilinguals, and report clear language dominance effects on all response measures (including number of correct responses, 
first-response latencies and mean response latency). These findings were interpreted as evidence of uni-directional cross-language interference, such that the dominant language interferes with the non-dominant one. In the present study, verbal fluency is not necessarily viewed as the sole determinant of language dominance, the assessment of which is a much debated issue (see Fledge et al. 2002). The rationale for its selection as categorisation criterion lies in its potential to provide a reliable measure of relative language ability in highly fluent bilinguals. While our bilingual participants performed at ceiling in grammaticality judgment tasks and self-reported maximum scores of comprehension and production in both languages, the group can be split into two distinct sub-groups in terms of verbal fluency (see information and statistics in section 2.1 below). This, in conjunction with the fact that self-reported measures are notoriously unreliable (Dörnyei 2010), renders verbal fluency the appropriate criterion for testing the hypothesis that relative language abilities in early bilinguals have an effect on syntactic co-activation. If relative verbal fluency has an effect on syntactic activation, and based on the directionality of findings in the field of lexical access reported above, then we expect the relatively more fluent (in Welsh) subgroup to show a stronger inhibition effect than the relatively less fluent subgroup. If relative verbal fluency does not have an effect on syntactic activation, then no between-group difference may be detected.

\section{Methods}




\subsection{Participants}

The sixteen Welsh-English bilingual participants that took part in Thierry and Sanoudaki (2012) were split into two subgroups of equal size, depending on participants' performance in a semantic verbal fluency task in English and Welsh. The verbal fluency task was administered to all bilingual participants and included eight semantic categories (clothing, animals, vegetables, fruits, body parts, musical instruments, occupations, furniture). Order of category presentation was randomised for each participant. Participants were instructed to name items belonging to the first four categories in English, and the remaining four in Welsh. For the purposes of the present study, participants were divided into two groups based on their relative fluency in the two languages. Note that for ease of exposition the two groups will be labelled as high and low Welsh fluency. This is not a reflection of the participants' absolute verbal fluency in Welsh; measure was calculated as the percentage of Welsh items in the participant's combined production in the two languages. Participants in the high Welsh fluency group had a higher percentage of Welsh items in their overall (English and Welsh) verbal fluency output than participants in the low Welsh fluency group.

Information on language use, proficiency and background was collected using self-completed questionnaires. All bilingual participants were brought up in Wales, in families where at least one of the parents was a bilingual Welsh-English speaker. All participants were first exposed to Welsh at home in infancy. Exposure to English commenced either at home from birth (three participants in each group) or during early childhood in the community. Of the six participants who were exposed to English at home, two participants (in the low fluency group) reported that each of their parents spoke to them in a different language (mother in English, father in Welsh, or the other way round). These two participants also had frequent contact with extended family who 
strengthened Welsh language input. With regard to education, two participants in the high Welsh fluency group and one participant in the low Welsh fluency group were first exposed to English at nursery; two participants in the low fluency group were first exposed to English formally at primary school and two participants in the high fluency group at secondary school. Finally, according to participant self-report, studies at university level were conducted either fully or mostly through the medium of English (about 20\% Welsh for seven participants in the high fluency group and two participants in the low fluency group).

A summary of the characteristics of the two groups can be found in table 1 . Participants also completed a grammaticality judgment test in English and in Welsh, in which they were asked to indicate whether or not each of 56 sentences was a possible English (or Welsh) sentence. Correct responses for the grammaticality judgment task were above $80 \%$ for all participants, and individual results can be found in the appendix. As part of the grammaticality judgment task, sentences that involved adjective-noun pairs were tested (examples from the English task).

(1) The little boy is under the table. (grammatical)

(2) *The lion big is under the tree. (ungrammatical)

The two bilingual groups performed at ceiling at the adjective-noun pair sequences of the grammaticality judgment task, in both languages.

Table 1 about here

Independent samples t-tests showed that the two sub-groups differed significantly in their performance in the fluency task in terms of the percentage of correct responses in Welsh, $\mathrm{t}(14)=-4.178, \mathrm{p}=.001$, while they did not differ 
significantly in any of the other measures (grammaticality judgment test in English, $\mathrm{t}(14)=1.239, \mathrm{p}=.236$, and in Welsh, $\mathrm{t}(14)=1.632, \mathrm{p}=.127$, percent use of English, $\mathrm{t}(14)=0.307, \mathrm{p}=.763$, age when they started to speak English, $\mathrm{t}(14)=.966, \mathrm{p}=.35$, age when they started to speak Welsh, $\mathrm{t}(14)=-1, \mathrm{p}=.334$.)

Eight participants were randomly selected from the English monolingual group in Thierry and Sanoudaki (2012) to form a control group (age range 18-22, mean age 19.8, seven women, seven right-handed). All participants had normal or corrected-tonormal vision and no symptoms or history of developmental dyslexia. The experiment was approved by the ethics committee of the School of Psychology, Bangor University.

\subsection{Materials}

Using line drawings of six objects (book, phone, car, pen, box, shirt) and eight colours (red, blue, yellow, green, pink, brown, white, black), we created a total of forty-eight coloured images. We paired each of the forty-eight images with a colour adjective and noun such that the adjective either matched the colour of the picture or not (adjective match/mismatch), and similarly, the noun either matched the picture or not (noun match/mismatch). For each adjective and noun sequence, the order could be either correct or incorrect, depending on whether the adjective preceded (e.g. blue pen) or followed the noun (e.g. pen blue). The latter order is not possible in English, but the phrase would be grammatical if translated into Welsh word-by-word.

The experimental design therefore involved eight conditions, in a fully balanced two-by-two-by-two design. In (3) below we give an example of the different conditions by listing the sequences paired with the image of a red box.

(3) Sequences paired with image of red box

- $\quad$ red box 
- box red

- blue box

- box blue

- $\quad$ red pen

- pen red

- blue pen

- pen blue

- box

- pen

As can be seen, we also included two filler conditions, in which the noun (match or mismatch) was presented unaccompanied by a colour adjective. These were included to prevent participants from forming a systematic expectancy of an adjective upon seeing a noun in first position. This resulted in a total of 480 trials overall. Finally, each verbal stimulus was incorporated into a sentence indicating the position of the object on the screen (left or right), as in "The blue box was on the right".

\subsection{Experimental design and procedure}

\subsubsection{Overall procedure}

Participants first filled in a language background questionnaire (adapted from Gathercole et al. 2010), followed by the grammaticality judgment task and the verbal fluency task. Participants were then invited to wash their hair using baby shampoo in order to minimise scalp impedance, and were accompanied to a soundproofed room where the ERP experiment took place, after which they were debriefed. During debriefing, none of the participants reported awareness of the relevance of Welsh noun- 
adjective order in the experiment. Instructions were given in English, and the experimenter was not a Welsh speaker.

\subsubsection{ERP task}

For each experimental trial, participants saw an image followed by a sentence, constructed as described above (section 2.2 Materials), and were asked to respond only when either the colour (adjective) or the object (noun) mentioned in the sentence matched the picture's characteristics, and to refrain from responding if neither the colour nor the object matched the picture. Response involved pressing a keyboard key set under their left or right index fingers depending on whether the position mentioned in the sentence (left/right) matched the position of the image on the screen or not. For example, upon viewing the picture of a red box on the right side of the screen followed by the sequence 'The red box was on the right' (or any of the following: 'The box red/ red pen/ pen red/ blue box/ box blue/ box was on the right'), participants had to press the designated yes key. If the sequence was 'The red box was on the left', they would need to press the designated no key, while if the sequence corresponded to any of the following 'The blue pen/ pen blue/ pen was on the left/ right', then no answer was required. In terms of the mental decision task, conditions where the first word of the adjective and noun pair matches the picture (match conditions), required the participant to prepare to respond, while conditions where the first word does not match the image (mismatch conditions) required the participant to wait for the second word in order to decide whether to respond or not.

Images were presented on a computer screen either to the left or the right of a fixation cross for $200 \mathrm{~ms}$. Following a $500 \mathrm{~ms}$ interval, the sentence was presented in chunks of isolated words and small phrases (The/ red/ box /was/ on the right). Each of the chunks was presented for $200 \mathrm{~ms}$ at the centre of the screen in order to avoid ERP 
contamination by eye movements. Each of the chunks was followed by an interval of $500 \mathrm{~ms}$, while the critical stimuli of nouns and adjectives were followed by a longer interval $(800 \mathrm{~ms})$ so as to allow for ERP measurements. At the end of each trial, a question mark was presented at the centre of the screen, displayed for $2000 \mathrm{~ms}$ during which participant response was expected. There was a $2000 \mathrm{~ms}$ inter-trial interval.

Before the start of the EEG acquisition, participants were presented with fifteen practice trials different from test trials, involving feedback from the experimenter. If seventy percent response accuracy was not achieved at the end of the fifteen trials, practice was repeated for a maximum of two times until threshold accuracy was achieved. The experiment was divided in six blocks of eighty trials each. Trial order was randomised, and response side was counterbalanced between participants.

\subsection{ERP recording and analysis}

Electrophysiological data were recorded in reference to $\mathrm{Cz}$ at a rate of $1 \mathrm{kHz}$ from 64 $\mathrm{Ag} / \mathrm{AgC} 1$ electrodes placed according to the 10-20 convention. Impedances were kept below $7 \mathrm{k} \Omega$. EEG activity was filtered on-line band pass between $0.1 \mathrm{~Hz}$ and $200 \mathrm{~Hz}$, and off-line with a $30 \mathrm{~Hz}$ low-pass zero phase shift digital filter. Eye blinks were monitored using vertical electro-oculogram channels (VEOG) set above and below the right eye. Ocular artefacts were mathematically corrected when the variance of the eye blink model was below 0.005. EEG files were visually inspected for remaining artefacts and contaminated periods were manually excluded. Continuous recordings were cut into epochs, which ranged from $-100 \mathrm{~ms}$ to $1000 \mathrm{~ms}$ after the onset of critical (adjective or noun) stimuli. Baseline correction was performed in reference to pre-stimulus activity and individual averages were digitally re-referenced to the global average reference. Finally, grand-averages were calculated for each condition. Peak detection was carried out automatically, time-locked to the latency of the peak at the electrode of maximal 
amplitude on the grand-average ERP. The N2 component was studied in the 260-360 ms time window, at electrodes FC1, FC2, FCZ, and FZ. ERP data were subjected to repeated measures analyses of variance (ANOVAs) with congruence (match/mismatch) and speech-part (adjective/noun) as the primary factors of interest.

\section{Results}

The N2 elicited by the critical word (adjective or noun in first position) in all conditions was significantly modulated by factors speech-part (adjective-noun): $F(1,21)=12.433$, $\mathrm{p}=0.002$, and congruence (match-mismatch): $\mathrm{F}(1,21)=38.841 \mathrm{p}<0.001$. There was also a significant triple interaction between speech-part, congruence and group: $\mathrm{F}(2,21)$ $=37.262, p<0.001$ while there was no interaction between speech-part and group: $F(2$, $21)=0.587, p>0.1$ and no interaction between congruence and group $F(2,21)=1.863$, $\mathrm{p}>0.1$

Follow-up analyses performed to adjective-first conditions revealed a main effect of congruence $F(1,21)=19.057, p<0.001$, no effect of group $F(2,21)=0.456$, $p$ $>0.1$ and no congruence by group interaction: $\mathrm{F}(2,21)=2.05, \mathrm{p}>0.1$. The $\mathrm{N} 2$ component elicited by mismatching adjectives was more negative-going than that elicited by matching adjectives.

Figure 1 near here

In noun-first conditions, there was a main effect of congruence: $F(1,21)=$ $25.807, \mathrm{p}<0.001$, but this time a congruence by group interaction was also detected: $\mathrm{F}(2,21)=3.481, \mathrm{p}=0.049$. In follow-up analyses for each group in this condition, a main effect of congruence was present in the case of the high Welsh fluency bilingual group: $\mathrm{F}(1,7)=28.399, \mathrm{p}=0.001$, such that the $\mathrm{N} 2$ elicited by mismatching nouns was 
more negative-going than that elicited by matching nouns. This comparison did not reach significance in the case of the low Welsh fluency bilingual group: $\mathrm{F}(1,7)=4.198$, $\mathrm{p}=0.08$ or the monolingual control group: $\mathrm{F}(1,7)=2.552, \mathrm{p}=0.154$

Figure 2 near here

Overall, in adjective-first conditions, a difference was detected between match and mismatch conditions in the modulation of the $\mathrm{N} 2$ component, while for noun-first conditions, this difference was only present in the case of the high Welsh fluency group, and not in the low Welsh fluency group or the monolingual control group.

\section{Discussion}

The present paper evenly split the Welsh-English bilingual participants that participated in the Thierry and Sanoudaki (2012) study into two groups based on relative verbal fluency in their two languages, in order to investigate to what extent non selective syntactic activation is affected by relative language abilities. We examined electrophysiological evidence obtained through a mental decision task which tested participants' response inhibition in anticipation of grammatical and ungrammatical elements within English sentences. High Welsh fluency bilinguals showed response inhibition effects in anticipation of an adjective following a noun, as evidenced by modulation of the N2 component, while low Welsh fluency bilinguals did not, resembling English monolinguals. These results suggest that the unconscious and automatic activation of Welsh syntax (and in particular the noun-adjective word order) in English sentence comprehension is limited to participants with relatively higher Welsh verbal fluency. 
The results are in line with findings in the domain of lexical access, showing greater permeability from the stronger to the weaker language (Kroll et al. 2012, see e.g. Weber and Cutler 2004). This does not necessarily mean that the opposite is not possible, as permeability in the L2 to L1 direction can be detected in lexical access under certain conditions (see Kroll et al. 2012). For example, van Wijnendaele and Brysbaert (2002) provide evidence of phonological priming from the second (and weaker) to the first (and stronger) language of French-Dutch bilinguals. This type of finding has been central in the theoretical debate on word recognition models, serving as arguments for models that can better account for non-selective lexical access, such as the Bilingual Interactive Activation Plus model (Dijkstra and van Heuven 2002 - for a characteristic example of this debate, see Brysbaert and Duyck 2010 versus Kroll et al. 2010). Similarly, syntactic permeability may be bidirectional, but much more research is needed to establish this and the constraints which affect this cross-language interaction.

The present study provides new data in a research area where very little is currently known, as electrophysiological research on bilingual syntactic processing has so far focussed on the process of language learning, and especially on early stages of learning a second language in adult/late learners. Most of the existing research examines sensitivity to syntactic violations, and the question that is typically asked is when and if syntactic processing of a second language becomes native-like (e.g. Hahne and Friederici 2001; Weber-Fox and Neville 1996). The main elements examined in the relevant literature have been age of acquisition and proficiency as factors that differentiate second language processing from monolingual processing (see Kotz 2009 for a review). This research direction (also typical in research using different techniques, e.g. Pliatsikas and Marinis 2013) has moved attention away from the long 
suggested and strongly supported hypothesis that language processing in each of the two languages, even in early highly proficient bilinguals, is not the same as the processing of these languages in monolinguals (Grosjean 1992). The context of stable bilingualism in Wales (see Gathercole and Thomas 2009), where the present study was conducted, allowed us to examine syntactic processing in subgroups of highly proficient bilingual participants who had been exposed to both languages since early childhood. The current study is a significant addition to the very few ERP studies which searched for effects of cross-language interactions in syntax (Tokowicz and MacWhinney 2005, see also Bourguignon et al. 2010). Tokowicz and MacWhinney (2005) hypothesised that implicit responses to grammaticality violations in a second language may differ depending on whether the first language uses a similar or a conflicting structure. This hypothesis was supported by the findings of a pilot study which tested language comprehension in English learners of Spanish at the early stages of second language learning (Tokowicz and MacWhinney 2005). The current study supports and extends this by offering evidence for the role of language abilities in the processing of conflicting structures in the bilinguals' two languages. The fact that implicit responses were found to differ depending on relative language abilities supports the hypothesis that the effect is due to the presence of a conflicting word order in Welsh and English, and not due to a generic property of bilingual processing, as one could have hypothesised by examining the results of the Thierry and Sanoudaki (2012) study only.

Note that the observed effect constitutes an automatic, unconscious response to experimental stimuli. The ERP method is particularly suited to the detection of nonreflective, implicit responses to stimuli (e.g. Rugg et al. 1998). Early components in particular, such as the N2 which was detected here, are generally thought to indicate 
automatic aspects of processing (Patel \& Azzam, 2005). The implicit nature of the response means that behavioural measures would not necessarily show evidence of the effect observed here. Precisely, performance at the grammaticality judgment task (including the noun-adjective conditions), did not reveal any group effect. Even though the grammaticality judgment task is not directly comparable to our ERP task, this result indicates that, when explicitly asked, participants reject the Welsh word order in an English text. The use of ERPs allowed us to detect activation and availability of the Welsh word order in (high Welsh fluency) bilingual speakers, despite absence of such evidence in their conscious judgment.

The present study provides new evidence on bilingual syntactic access, while it does not directly contribute to the debate on the nature of syntactic representations in bilingualism. In a much cited study, Hartsuiker et al. (2004) argue for shared syntactic representations in bilingualism, on the basis of cross-language syntactic priming effects in Spanish-English bilinguals. According to Hartsuiker et al. (2004), grammatical structures in bilingual representations are unspecified for language (while words are specified for language). Although our findings are consistent with this view, they would also be consistent with the view whereby syntactic structures/rules are stored separately for each language, provided that simultaneous activation of corresponding structures is allowed. Under the latter approach, our results suggest that when Welsh-English bilinguals encounter an English noun within an English sentence, the Welsh nounadjective word order is also activated. A comparison of the two accounts falls beyond the scope of the present study: evaluation of the shared-representation versus simultaneous syntactic activation accounts would require further theoretical and experimental work, and would involve a range of syntactic theoretical assumptions (as is the case in the Hartsuiker et al. 2004 study). Our study (including our original 
analysis, Thierry and Sanoudaki 2012) aims to provide largely theory-neutral data, whose conservative interpretation involves cross-language syntactic activation; this activation results in response inhibition in bilinguals, who, unlike monolinguals, are able to anticipate information from an impending post-nominal adjective.

The split between bilinguals in the present analysis of the Thierry and Sanoudaki (2012) study suggests that this syntactic activation, even in highly proficient, early bilinguals, is affected by relative language abilities. Our study does not provide information on the exact nature of this dependency: we only tested one structure in one language pair using one experimental design and two participant groups, and much more research is needed. In an admission, perhaps, of how little knowledge we possess in relation to syntactic processing in bilinguals, Hernández, Fernández, and Aznar-Besé (2009) talk of a "model in which multiple constraints play a role in determining the nature of bilingual sentence processing" (2009:380); the present study indicates that one of these constraints is relative verbal fluency, even in early, highly proficient bilinguals.

\section{Conclusion}

The Welsh context in which this study was conducted offered us access to early, highly proficient bilinguals; it allowed us to find evidence of automatic, unconscious crosslanguage syntactic activation in this population and to provide a first indication that cross-language syntactic access may be constrained by relative language abilities.

\section{Appendix}

Table 2 around here 
Table 3 around here

\section{References}

Bourguignon, N., K. Kasparian, J. E. Drury, and K. Steinhauer. 2010. "L1 grammar influences L2 processing: ERP evidence of transfer effects." Paper presented at the 11th International Science of Aphasia Conference, Potsdam, Germany.

Brysbaert, M., and W. Duyck. 2010. "Is it time to leave behind the revised hierarchical model of bilingual language processing after 15 years of service?" Bilingualism: Language and Cognition, 13: 359-371.

Costa, A., M. Miozzo, and A. Caramazza. 1999. "Lexical Selection in Bilinguals: Do Words in the Bilingual's Two Lexicons Compete for Selection?” Journal of Memory and Language, 41 (3): 365-397.

Dijkstra, T., J. Grainger, and W. J. B van Heuven. 1999. "Recognition of cognates and interlingual homographs: the neglected role of phonology." Journal of Memory and Language 41: 496-518.

Dijkstra, T., and W. J. B. van Heuven. 2002. "The architecture of the bilingual word recognition system: from identification to decision." Bilingualism: Language and Cognition 5: 175-197.

Dörnyei, Z. 2010. Questionnaires in second language research: Construction, administration, and processing (2nd ed.). London: Routledge.

Duyck, W. 2005. "Translation and associative priming with cross-lingual pseudohomophones: Evidence for nonselective phonological activation in bilinguals." Journal of Experimental Psychology: Learning, Memory, and Cognition 31: 1340-1359.

Fledge, J. E., I. R. A. Mackay, and T. Piske. 2002. “Assessing bilingual dominance.” Applied Psycholinguistics 23: 567-598.

Gathercole, V. C. M., and E. M. Thomas. 2009. "Bilingual first-language development: Dominant language takeover, threatened minority language take-up." Bilingualism: Language and Cognition 12 (02): 213-237.

Gathercole, V.C.M, E. M. Thomas, L. Jones, N. V. Guasch, N. Young, and E. K. Hughes. 2010. "Cognitive effects of bilingualism: digging deeper for the contributions of language dominance, linguistic knowledge, socio-economic 
status and cognitive abilities.” International Journal of Bilingual Education and Bilingualism 13 (5): 617-664.

Grosjean F. 1992. “Another view of bilingualism.” In Cognitive Processing in Bilinguals, edited by R. Harris, 51-62. New York: Elsevier.

Hahne, A., and A.D. Friederici. 2001. "Processing a second language: late learners' comprehension mechanisms as revealed by event-related brain potentials." Bilingualism: Language and Cognition 4: 123-141.

Hartsuiker, R. J., M. J. Pickering, and E. Veltkamp. 2004. "Is Syntax Separate or Shared Between Languages?: Cross-Linguistic Syntactic Priming in Spanish-English Bilinguals." Psychological Science 15: 409-414.

Hernández, A. E., E. M. Fernández, and N. Aznar-Besé. 2009. "Bilingual sentence processing." In Oxford Handbook of Psycholinguistics, edited by G. Gaskell, 371-384. Oxford: Oxford University Press.

Von Holzen, K., and N. Mani. 2012. "Language nonselective lexical access in bilingual toddlers. ” Journal of Experimental Child Psychology 113 (4): 569-586.

Hoshino, N., and J. F. Kroll. 2008. "Cognate effects in picture naming: Does crosslanguage activation survive a change of script?" Cognition 106: 501-511.

Jared, D., and J. F. Kroll. 2001. "Do Bilinguals Activate Phonological Representations in One or Both of Their Languages When Naming Words?” Journal of Memory and Language 44: 2-31.

Kotz, S.A. 2009. "A critical review of ERP and fMRI evidence on L2 syntactic processing." Brain and Language 109: 68-74.

Kroll, J. F., P. E. Dussias, C. A. Bogulski, and J. R. Valdes-Kroff. 2012. "Juggling two languages in one mind: What bilinguals tell us about language processing and its consequences for cognition" in Psychology of Learning and Motivation, Volume 56, edited by B. Ross, 229-262, San Diego: Academic Pres

Kroll, J. F., J. G. Van Hell, N. Tokowicz, and D. W. Green. 2010. “The Revised Hierarchical Model: A critical review and assessment." Bilingualism: Language and Cognition, 13: 373-381.

Kroll, J.F., and S. E. Stewart. 1994. "Category interference in translation and picture naming: evidence for asymmetric connections between bilingual memory representations." Journal of Memory and Language 33: 149-174. 
Patel, S.H., and P.N. Azzam. 2005. "Characterization of N200 and P300: Selected studies of the event-related potential" International Journal of Medical Science 2:147-154.

Pliatsikas, C., and T. Marinis. 2013. "Processing empty categories in a second language. When naturalistic exposure fills the (intermediate) gap." Bilingualism, Language and Cognition 16: 167-182.

Poarch, G. J., and J. G. van Hell. 2012. “Cross-language activation in children's speech production: Evidence from second language learners, bilinguals, and trilinguals." Journal of Experimental Child Psychology 111: 419-438.

Rugg, M. D., Mark, R. E., Walla, P., Schloerscheidt, A. M., Birch, C. S., and Allan, K. 1998. "Dissociations of the neural correlates of implicit and explicit memory." Nature 392: 595-598.

Sandoval, T. C., T. H. Gollan, V. S. Ferreira, and D. P. Salmon. 2010. "What causes the bilingual disadvantage in verbal fluency? The dual-task analogy." Bilingualism: Language and Cognition 13: 231-252.

Thierry, G., and E. Sanoudaki. 2012 “Activation syntaxique non-sélective à la langue chez le bilingue précoce." Revue Française de Linguistique Appliquée 17 (2): 33-48.

Thierry, G., and Y.J. Wu, 2007. "Brain potentials reveal unconscious translation during foreign language comprehension". Proceedings of the National Academy of Sciences 104: 12530-12535.

Tokowicz, N., and B. MacWhinney. 2005. "Implicit and explicit measures of sensitivity to violations in second language grammar: An event-related potential investigation.” Studies in Second Language Acquisition 27: 173-204.

van Hell, J. G. and T. Dijkstra. 2002. "Foreign language knowledge can influence native language performance in exclusively native contexts." Psychonomic Bulletin and Review 9 (4): 780-9.

Van Wijnendaele, I., and M. Brysbaert. 2002. "Visual word recognition in bilinguals: Phonological priming from the second to the first language." Journal of Experimental Psychology: Human Perception and Performance 28 (3): 616-627.

Weber, A., and A. Cutler. 2004. "Lexical competition in non-native spoken-word recognition." Journal of Memory and Language 50 (1): 1-25. 
Weber-Fox, C. M., and H. J. Neville. 1996. "Maturational constraints on functional specializations for language processing: ERP and behavioral evidence in bilingual speakers." Journal of Cognitive Neuroscience 8: 231-256.

Wu, Y. J., and G. Thierry. 2010. "Chinese-English bilinguals reading English hear Chinese." The Journal of Neuroscience 2: 7646-7651. 
Table 1. Summary of bilinguals' details. ( $\mathrm{SD}=$ standard deviation $)$

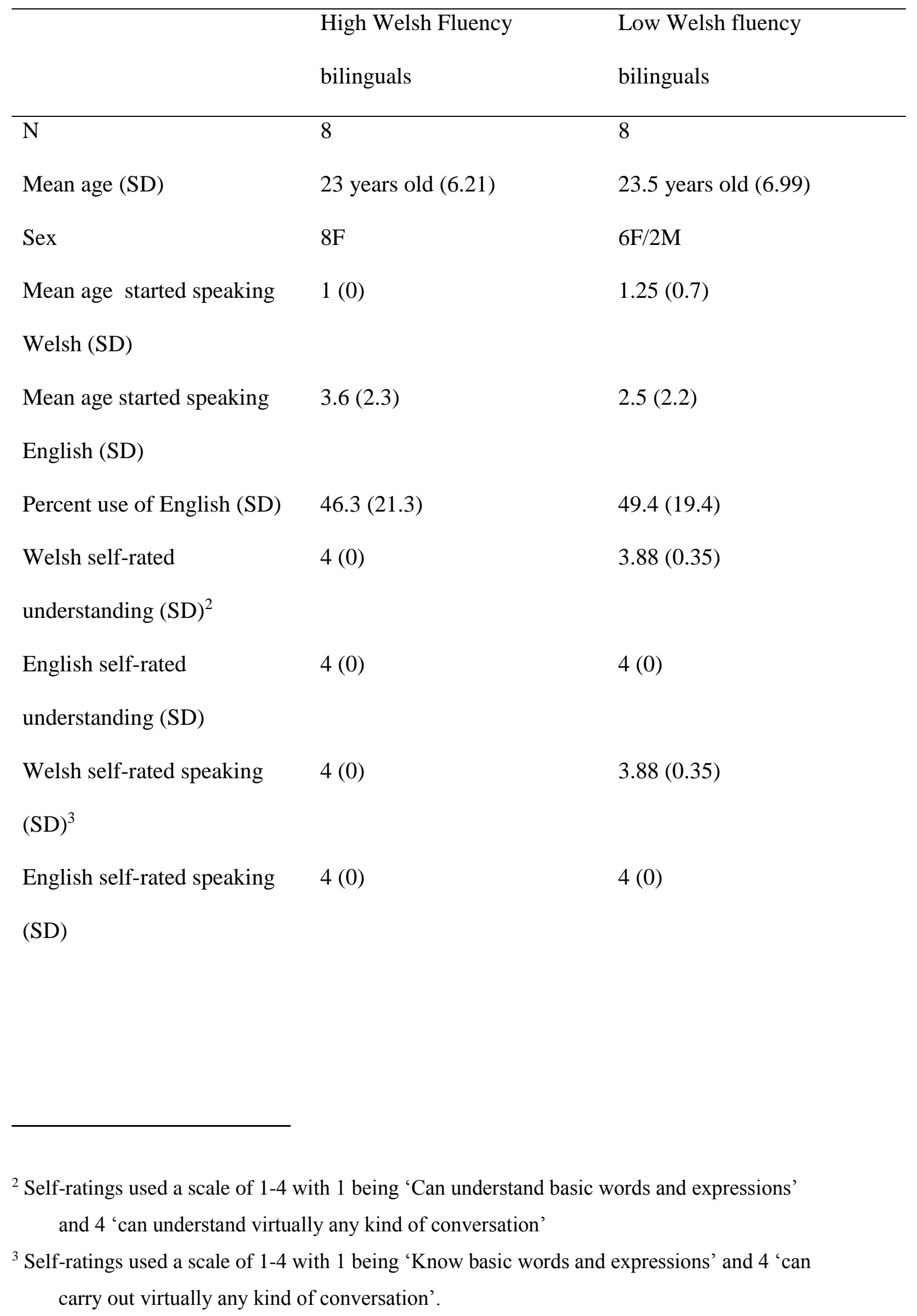


Percent target in Welsh

grammaticality judgment

task (SD)

Percent target in English

grammaticality judgment

task (SD)
$92.4(4.4)$

$94.3(4.7)$

$94.2(6.5)$

$97.2(2.4)$ 
Table 2. Results of the verbal fluency task. Number of correct responses for all categories in each language. $\mathrm{LF}=$ Low fluency group. $\mathrm{HF}=$ High fluency group

\begin{tabular}{cccc}
\hline Group and participant number & English (raw numbers) & Welsh (raw numbers) & Percent Welsh \\
\hline LF1 & 63 & 31 & 32.9 \\
LF2 & 57 & 34 & 37.4 \\
LF3 & 47 & 31 & 39.7 \\
LF4 & 52 & 35 & 40.2 \\
LF5 & 59 & 40 & 40.4 \\
LF6 & 55 & 38 & 40.9 \\
LF7 & 40 & 28 & 41.2 \\
LF8 & 39 & 28 & 41.8 \\
HF1 & 38 & 28 & 42.4 \\
HF2 & 45 & 34 & 43.4 \\
HF3 & 39 & 31 & 44.3 \\
HF4 & 44 & 35 & 44.3 \\
HF5 & 47 & 38 & 44.7 \\
HF6 & 52 & 48 & 48 \\
HF7 & 53 & 56 & 51 \\
HF8 & 51 & 55 & 51.9 \\
\hline
\end{tabular}


Table 3. Results of the grammaticality judgment task

\begin{tabular}{ccc}
\hline Group and participant number & English (percent target) & Welsh (percent target) \\
\hline LF1 & 100 & 95.8 \\
LF2 & 96.3 & 87.5 \\
LF3 & 92.6 & 87.5 \\
LF4 & 98.1 & 97.9 \\
LF5 & 96.3 & 87.5 \\
LF6 & 98.1 & 95.8 \\
LF7 & 96.3 & 95.8 \\
LF8 & 100 & 91.7 \\
HF1 & 100 & 100 \\
HF2 & 94.4 & 93.8 \\
HF3 & 98.1 & 97.9 \\
HF4 & 83.3 & 87.5 \\
HF5 & 90.7 & 93.6 \\
HF6 & 100 & 97.9 \\
HF7 & 100 & 95.8 \\
HF8 & 87.5 \\
\hline
\end{tabular}



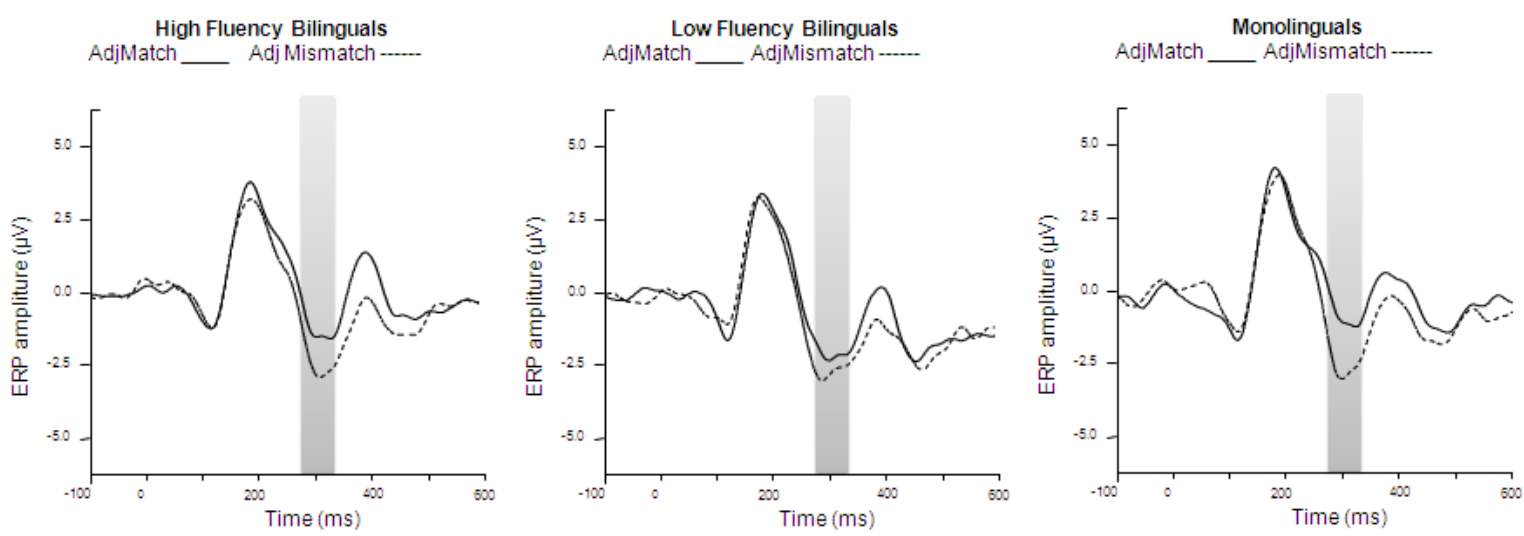

Figure 1. Averaged waveforms obtained from electrode FCZ for each of the language groups in the adjective match and mismatch conditions.
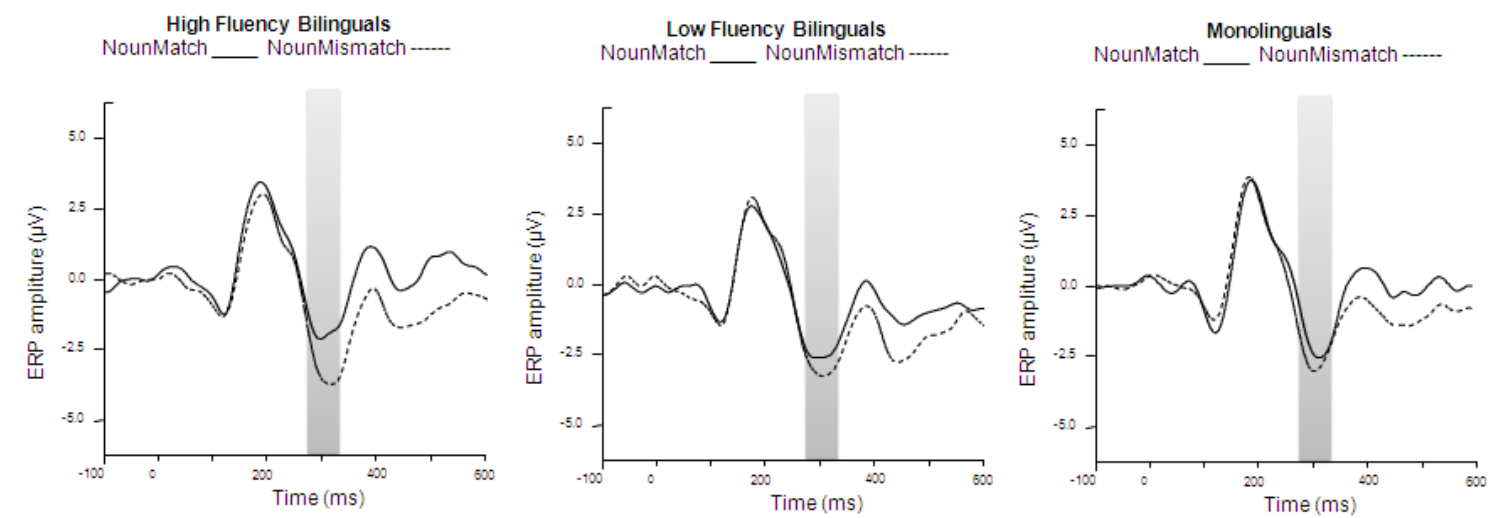

Figure 2. Averaged waveforms obtained from electrode FCZ for each of the language groups in the noun match and mismatch conditions. 